\title{
Correction: MicroRNA expression in pre-treatment plasma of patients with benign breast diseases and breast cancer
}

\section{Mirelle Lagendijk로 ${ }^{1}$ Sepideh Saadatmand ${ }^{1}$, Linetta B. Koppert ${ }^{1}$, Madeleine M.A. Tilanus-Linthorst ${ }^{1}$, Vanja de Weerd ${ }^{2}$, Raquel Ramírez-Moreno ${ }^{2}$, Marcel Smid ${ }^{2}$, Anieta M. Sieuwerts ${ }^{2,3}$ and John W.M. Martens ${ }^{2,3}$ \\ ${ }^{1}$ Department of Surgical Oncology, Erasmus MC Cancer Institute, EA 3075, Rotterdam, The Netherlands \\ 2 Department of Medical Oncology, Erasmus MC Cancer Institute, EA 3075, Rotterdam, The Netherlands \\ ${ }^{3}$ Cancer Genomics Centre Netherlands, Erasmus University MC, CN 3015, Rotterdam, The Netherlands \\ Published: August 10, 2018}

Copyright: Lagendijk et al. This is an open-access article distributed under the terms of the Creative Commons Attribution License 3.0 (CC BY 3.0), which permits unrestricted use, distribution, and reproduction in any medium, provided the original author and source are credited.

This article has been corrected: The correct author name is given below:

\section{Sepideh Saadatmand}

Original article: Oncotarget. 2018; 9:24335-24346. https://doi.org/10.18632/oncotarget.25262 